\title{
In vitro Biological Activities of the Anti-aging Potential of Dimocarpus longan Leaf Extracts
}

Pimjai Doungsaard $^{1}$, Sunee Chansakaow ${ }^{1}$, Jakkapan Sirithunyalug ${ }^{1}$, Lue Shang-Chian ${ }^{2}$, Lin Wei-Chao ${ }^{2}$, Liang Chia-Hua ${ }^{2}$, Lee Kuan-Ha ${ }^{3}$ and Pimporn Leelapornpisid ${ }^{*}$

\author{
${ }^{1}$ Department of Pharmaceutical Sciences, Faculty of Pharmacy, Chiang Mai \\ University, Chiang Mai 50200, Thailand \\ ${ }^{2}$ Department of Cosmetic Science and Institute of Cosmetic Science, Chia Nan \\ University, Tainan 71710, Taiwan \\ ${ }^{3}$ Department of Pharmacy, Chia Nan University, Tainan 71710, Taiwan
}

*Corresponding author.E-mail: pim_leela@hotmail.com https://doi.org/10.12982/CMUJNS.2020.0016

Received: March 4, 2018
Revised: June 14, 2019
Accepted: July 15, 2019

\section{ABSTRACT}

The longan (Dimocarpus longan Lour.) leaves, which are the underutilized part of trimming longan trees to increase their fruit productivity, were of interest in this study. They have been reported to contain phytochemical components which might be used for anti-aging purposes. In this study, longan leaves were extracted using two different solvents including $95 \%$ ethanol and $50 \%$ ethanol, named ethanolic extract (ET) and hydroethanolic extract $(\mathrm{HE})$, respectively. The extracts were investigated for antioxidation properties, inhibition of hyaluronidase, collagenase, MMP-2 and MMP-9 together with the determination of their total phenolic and flavonoid content. Additionally, HPLC-fingerprinting of the extract was performed. The results revealed that HE had a higher yield with the remarkable property of superior in vitro biological activity compared with ET. HE showed radical scavenging activity on DPPH and hydrogen peroxide with $\mathrm{IC}_{50}$ of $30.03 \pm 7.64$ and $71.40 \pm 15.30$ $\mu \mathrm{g} / \mathrm{ml}$, respectively. Moreover, it showed inhibition of lipid peroxidation with $I C_{50}$ of $537.01 \pm 42.32 \mu \mathrm{g} / \mathrm{ml}$. For inhibition against hyaluronidase and collagenase, $\mathrm{HE}$ was detected with $\mathrm{IC}_{50}$ of $234.80 \pm 21.52$ and $314.44 \pm 62.14$ $\mu \mathrm{g} / \mathrm{ml}$, respectively. The extract also demonstrated MMP-2 and MMP-9 inhibition, which is more potent than gallic acid as determined by zymography at $1.0 \mathrm{mg} / \mathrm{ml}$. In conclusion, hydroethanolic extract $(\mathrm{HE})$ of longan leaves presented high potential as in vitro antioxidant and inhibitor of enzymatic 


\section{activities. It might be a promising approach to the further development of anti-aging products.}

Keywords: Longan leaves, Antioxidant activity, Anti-hyaluronidase activity, Anti-collagenase activity, Inhibition of MMP-2 and MMP-9 assay

\section{INTRODUCTION}

Aging is associated with a progressive deterioration of cells that is a major risk factor for developing many degenerative diseases such as cardiovascular disease, neurodegenerative disease and even skin aging (Denicola and LopezAlarcon, 2013). Skin aging involves the degradation of extracellular matrix (ECM) in both epidermal and dermal layers. The results lead to skin dryness, thinning and sagging, while the loss of structure and integrity diminishes the skin's ability to protect the body and detect changes in temperature and pressure. Aging skin tends to be sensitive to infection, trauma and pressure ulcers (Davies, 2008).

Aging skin is caused by intrinsic and extrinsic factors. Exposure to sun rays and air pollution increases Reactive Oxygen Species (ROS) generation in the skin and induces oxidative stress. Oxidative damage may lead to lipid peroxide formation, mitochondrial and DNA damage and protein and gene modification, which alter protein structure and function. ROS also increases matrix metalloproteinase enzymes (MMPs) in the skin cells (Mukherjee et al., 2011). The combined actions of collagenase (MMP-1), $92 \mathrm{kDa}$ gelatinase (MMP-2) and $72 \mathrm{kDa}$ gelatinase (MMP-9) can fully degrade skin collagen and components of the elastic network. Collagenase is capable of cleaving in the triple helical domain of collagen. Furthermore, the denatured collagen can be further broken down by gelatinase (Jenkins, 2002). Hyaluronic acid is a predominant voluminous molecule in ECM. It plays a significant role in the maintenance of extracellular space, facilitate the transportation of nutrients and preserve tissue hydration (Manuskiatti and Maibach, 1996). Reduction of oxidative stress, as well as inhibition of enzymatic activities of collagenase, hyaluronidase, MMP-2, and MMP-9, can be used to evaluate anti-aging activity.

While considerable attention has been paid to plant components to replace synthetic additives, phytochemical components such as phenolics, flavonoids and terpenoids have been widely investigated and have shown anti-aging properties (Kim et al., 2008; Mukherjee et al., 2011).

Longan (Dimocarpus longan Lour.) is a member of the Sapindaceae family, widely distributed in China and Southern Asia, including Thailand, Vietnam and the Philippines (Yuge, 2012). Longan leaves have been reported to contain phenolics, flavonoids, terpenoids and sterols (Yuge, 2012; Xue et al., 2015). The longan leaf extract has shown high antioxidant activity, anti-hepatitis 
C virus, anti-hyperuricemia and anticancer activity (Rashed and Fouche, 2013; Apriyanto et al., 2016; Sheu et al., 2016). However, there are few reports of antiaging benefits.

This study aims to investigate the potential of longan (Dimocarpus longan cv. Daw) leaf extracts for anti-aging properties via antioxidation and inhibition of hyaluronidase, collagenase, MMP-2 and MMP-9 together with the determination of their total phenolic and flavonoid content. Also, HPLCfingerprint on the extract were performed.

\section{MATERIALS AND METHODS}

\section{Chemicals and reagents}

1,1-Diphenyl-2-picrylhydrazyl (DPPH), linoleic acid, 2,2'-Azobis(2amidinopropane) dihydrochloride (AAPH) and aluminium chloride were purchased from Fluka (Buchs, Switzerland). Acetonitrile, ammonium thiocyanate, boric acid, calcium chloride, Folin-Ciocalteu's reagent, hydrogen peroxide, iron (II) chloride tetrahydrate, sodium borate, sodium metaborate and sodium nitrite were purchased from Merck (Darmstadt, Germany). Trolox, quercetin, gallic acid, hyaluronic acid sodium salt from Streptococcus equi, hyaluronidase from bovine testes, 4-dimethylaminobenzaldehyde (DMAB), collagenase type 1A from Clostridium histolyticum, bovine collagen-1, 3, 4-dihydroxyphenaylacetic acid (3,4-DHPAA) and sodium periodate were purchased from Sigma (St. Louis, MO). Bis-acrylamide, protein marker and sodium dodecyl sulfate were purchased form Bio-Rad Laboratories (Richmond, United Kingdom). Bromophenol blue, Coomassie brilliant blue, Dulbecco's medium, Newborn calf serum (NCS), trypsin, penicillin, streptomycin and Tris-HCl buffer were purchased from GeneDirex, Inc. (Taiwan).

\section{D. longan leaf extracts preparation}

The leaves of $D$. longan cv. Daw were collected from Hang Dong District, Chiang Mai Province between April and May. The leaves were then washed thoroughly with tap water and dried at $50{ }^{\circ} \mathrm{C}$ for 24 hours, after which they were blended into a fine powder using an industrial blending machine. The dried leaf powder $(500 \mathrm{~g})$ was macerated with $95 \%$ ethanol or $50 \%$ ethanol at room temperature for 48 hours with occasional stirring. The solutions were filtered with Whatman's No.1 filter membrane and evaporated using rotary evaporator (R-300 Buchi $^{\circledR}$, Flawil, Switzerland) at $50{ }^{\circ} \mathrm{C}$. The extraction was repeated three times, and all the extracts were pooled. The extracts were named as ethanolic extract (ET) and hydroethanolic extract (HE).

\section{Determination of antioxidant activity}

DPPH-radical scavenging assay. Scavenging activity of the extracts on DPPH radical was determined using the method of Kiattsin et al. (2016) with some modifications. The extracts were dissolved in ethanol in the concentration 
range of $0.01-1 \mathrm{mg} / \mathrm{ml}$. The aliquot of sample $(20 \mu \mathrm{l})$ was mixed with $120 \mathrm{mM}$ DPPH in ethanol $(180 \mu \mathrm{l})$ and kept in the dark for 30 minutes. Then the absorbance of the solution was measured at $520 \mathrm{~nm}$ using microplate reader (SPECTROstar Nano ${ }^{\circledR}$, Ortenberg, Germany). The mixture of the sample with ethanol was served as a blank. The absorbance of control was determined by replacing the sample with ethanol. Trolox, gallic acid and quercetin were used as positive control. The $\mathrm{IC}_{50}$ value, which was the concentration of the sample that scavenged $50 \%$ of the DPPH radical, was determined. The percentage of inhibition was calculated using the following equation:

Inhibition $(\%)=\left[\left(\mathrm{Abs}_{\text {control }}-\mathrm{Abs}_{\text {sample }}\right) / \mathrm{Abs}_{\text {control }}\right] \times 100$

Hydrogen peroxide scavenging $\left(\mathrm{H}_{2} \mathrm{O}_{2}\right)$ assay. The ability of plant extracts to scavenge hydrogen peroxide can be estimated according to the method of Ruch et al. (1989). A solution of hydrogen peroxide (4 mM) was prepared in phosphate buffer (5 $\mathrm{mM} \mathrm{pH} \mathrm{7.4).} \mathrm{The} \mathrm{extracts} \mathrm{were} \mathrm{dissolved} \mathrm{in} 20 \%$ Tween 20 in distilled water in the concentration range of $0.1-10 \mathrm{mg} / \mathrm{ml}$. The aliquot of sample $(100 \mu \mathrm{l})$ was mixed with hydrogen peroxide solution $(5 \mathrm{ml})$ and allowed to stand for 10 minutes. Then the concentration of hydrogen peroxide was determined by absorption at $230 \mathrm{~nm}$ using cuvette port of spectrophotometer (SPECTROstar Nano ${ }^{\circledR}$, Ortenberg, Germany). The mixture of the sample with phosphate buffer was served as a blank. The absorbance of the control was determined by replacing the sample with $20 \%$ Tween 20 in distilled water. Trolox, gallic acid and quercetin were used as positive control. The $\mathrm{IC}_{50}$ value, which was the concentration of the sample that scavenged $50 \%$ of the hydrogen peroxide, was determined. The percentage of inhibition was calculated using the following equation:

Inhibition $(\%)=\left[\left(\mathrm{Abs}_{\text {control }}-\mathrm{Abs}_{\text {sample }}\right) / \mathrm{Abs}_{\text {control }}\right] \times 100$

Inhibition of Linoleic acid peroxidation assay. The inhibition of linoleic acid peroxidation of the extracts was determined using the methods of Olszewska (2011) with some modifications. Each of the extracts and standards was dissolved in $20 \%$ Tween 20 in deionized water in the concentration range of $10-50 \mathrm{mg} / \mathrm{ml}$. The aliquot of the sample $(100 \mu \mathrm{l}), 20 \mathrm{mM}$ Phosphate buffer $\mathrm{pH} 7.0(140 \mu \mathrm{l})$ and $1.3 \%$ linoleic acid in methanol $(140 \mu \mathrm{l})$ were added with $46.35 \mathrm{mM}$ AAPH solution $(20 \mu \mathrm{l})$ to start lipid peroxidation process in screw cap vial. The $20 \%$ Tween 20 in deionized water was used instead of sample as a control. The mixture was incubated in the dark at $50{ }^{\circ} \mathrm{C}$ for 4 hours or until the absorbance of the control was $0.550 \pm 0.020$ at $500 \mathrm{~nm}$. The degree of lipid peroxidation was determined by the ferric-thiocyanate method. The reaction mixture $(2.5 \mu \mathrm{l})$ was mixed with $20 \mathrm{mM} \mathrm{FeCl}_{2}$ solution in $3.5 \% \mathrm{HCl}(2.5 \mu \mathrm{l}), 10 \% \mathrm{NH}_{4} \mathrm{SCN}$ solution $(2.5 \mu \mathrm{l})$ and $75 \%$ methanol $(250 \mu \mathrm{l})$ for 3 minutes in a well of a 96-well microplate. The absorbance was measured at $500 \mathrm{~nm}$ using a microplate reader (SPECTROstar Nano ${ }^{\circledR}$, Ortenberg, Germany). Trolox, gallic acid and quercetin 
were served as positive control. The $\mathrm{IC}_{50}$ value, which was the concentration of the sample that reduced $50 \%$ of the linoleic peroxidation, was determined. The percentage of inhibition was calculated using the following equation:

Inhibition $(\%)=\left[\left(\mathrm{Abs}_{\text {control }}-\mathrm{Abs}_{\text {sample }}\right) / \mathrm{Abs}_{\text {control }}\right] \times 100$

\section{Determination of anti-hyaluronidase activity}

The fluorometric Morgan-Elson assay as modified by Takahashi et al., (2003) was followed. The extracts were dissolved in propylene glycol in the concentration range of $1-100 \mathrm{mg} / \mathrm{ml}$. The mixture of $12.5 \mathrm{mM}$ calcium chloride $(25 \mu \mathrm{l})$, test samples $(12.5 \mu \mathrm{l})$ and $1.5 \mathrm{mg} / \mathrm{ml}$ hyaluronidase in $20 \mathrm{mM}$ phosphate buffer pH $5.5(12.5 \mu \mathrm{l})$ was incubated in the dark at $37{ }^{\circ} \mathrm{C}$ for 20 minutes. The phosphate buffer was used instead of hyaluronidase solution as a blank. The propylene glycol was used instead of test sample as the control. Then, the substrate of $1 \mathrm{mg} / \mathrm{ml}$ hyaluronic acid in $0.1 \mathrm{M}$ acetate buffer $\mathrm{pH} 3.5(100 \mu \mathrm{l})$ was added, and the vial was incubated 60 minutes further at $37{ }^{\circ} \mathrm{C}$. Finally, the $0.8 \mathrm{M}$ sodium metaborate $(25 \mu \mathrm{l})$ was added, and the reaction was stopped by placing in a water bath $\left(100{ }^{\circ} \mathrm{C}\right)$ for 3 minutes. After cooling to room temperature, the 800 $\mu \mathrm{l}$ of DMAB reagent $(4 \mathrm{~g}$ DMAB in $40 \mathrm{ml}$ acetic acid and $5 \mathrm{ml}$ of $10 \mathrm{~N} \mathrm{HCl}$ ) was added and incubated for 20 minutes and the contents were transferred to their respective wells of the 96-well microplate. Fluorescence was detected using a multi-mode microplate reader (Spectramax M3 ${ }^{\circledR}$, San Jose, California) at $545 \mathrm{~nm}$ excitation and $612 \mathrm{~nm}$ emission. Gallic acid and quercetin were served as positive control. The $\mathrm{IC}_{50}$ value, which was the concentration of the sample that reduced $50 \%$ of enzymatic activity, was determined. The percentage of inhibition was calculated by the equation:

Inhibition $(\%)=\left[\left(\right.\right.$ Fluorescence intensity ${ }_{\text {control }}-$ Fluorescence intensity $\left._{\text {sample }}\right) /$ Fluorescence intensity control] x100

\section{Determination of anti-collagenase activity}

The inhibition of collagenase was determined using the methods of Yasmin et al., (2014) with some modifications. The extracts were dissolved with $20 \%$ Tween 20 in deionized water in the concentration range of $1-50 \mathrm{mg} / \mathrm{ml}$. The mixture of test samples $(30 \mu \mathrm{l}), 10 \mathrm{mM} \mathrm{CaCl}_{2}$ in $125 \mathrm{mM}$ borate buffer $\mathrm{pH} 7.5$ $(100 \mu \mathrm{l})$ and $0.1 \mathrm{mg} / \mathrm{ml}$ collagenase in $125 \mathrm{mM}$ borate buffer $\mathrm{pH} 7.5(50 \mu \mathrm{l})$ were incubated in screw cap vial in the dark at $37^{\circ} \mathrm{C}$ for 10 minutes. The borate buffer was used instead of collagenase solution as a blank. The $20 \%$ Tween 20 in distilled water was used instead of test sample as a control. The substrate of 80 $\mu \mathrm{g} / \mathrm{ml}$ collagen was added and the vial was incubated at $37^{\circ} \mathrm{C}$. After 60 minutes of incubation, the enzymatic solution $(200 \mu \mathrm{l})$ was mixed with $0.75 \mathrm{mM} \mathrm{3}$, 4-DHPAA, $125 \mathrm{mM}$ sodium borate $\mathrm{pH} 8(200 \mu \mathrm{l})$ and $1.25 \mathrm{mM}$ of $\mathrm{NaIO}_{4}$. The mixture was immediately reacted at $37{ }^{\circ} \mathrm{C}$ for 10 minutes and then kept in an ice water bath to stabilize the fluorophore. The fluorescence intensity of the reaction mixture was measured by multi-mode microplate reader (Spectramax M3 ${ }^{\circledR}$, San 
Jose, California) at $375 \mathrm{~nm}$ excitation and $465 \mathrm{~nm}$ emission. Gallic acid was served as positive control. The $\mathrm{IC}_{50}$ value, which was the concentration of the sample that reduced $50 \%$ of enzymatic activity, was determined. The percentage of inhibition was calculated using the following equation:

$$
\begin{aligned}
\text { Inhibition }(\%)= & {\left[\left(\text { Fluorescence intensity } y_{\text {control }}-\right.\right.\text { Fluorescence intensity }} \\
& \text { Fluorple }) / \\
\text { Fluoscence intensity control } & \text { x100 }
\end{aligned}
$$

\section{Determination of MMP-2 and MMP-9 inhibition}

The extracts were assayed for gelatinolytic activity of MMP-2 and MMP9 inhibition using the method of Lai and Lue (2017). The extracts were dissolved with deionized water in the concentration of $10 \mathrm{mg} / \mathrm{ml}$. Mouse embryonic fibroblasts (BCRC 60071; ATCC ${ }^{\circledR}$ CCL92) were cultured in 10\% DMEM, 10\% NCS and $1 \%$ antibiotic at $37{ }^{\circ} \mathrm{C}$ in a humidified atmosphere with $5 \% \mathrm{CO}_{2}$. The cells were sub-cultured every two days until fully grown. Then the culture medium was changed to DMEM without serum for 24 hours and harvested by centrifugation at $1,200 \mathrm{x}$ g for 5 minutes. Culture supernatants containing MMP$2(72 \mathrm{kDa})$ and MMP-9 $(92 \mathrm{kDa})$ were collected and incubated with the extract solution at $37{ }^{\circ} \mathrm{C}$ in a humidified atmosphere with $5 \% \mathrm{CO}_{2}$ for $24-48$ hours. To assess the gelatinolytic activities of MMP-2 and MMP-9, Sodium dodecyl sulfate-polyacrylamide gel electrophoresis (SDS-PAGE) zymography using gelatin as a substrate was performed. Briefly, the reaction mixture was suspended in loading buffer $(125 \mathrm{mM}$ Tris- $\mathrm{HCl} \mathrm{pH} 6.8,4 \%$ SDS, $0.1 \%$ bromophenol blue, and $3.2 \%$ glycerol). The reaction solutions $(20 \mu \mathrm{l})$ were run on SDS polyacrylamide gel containing gelatin with running buffer at 100-150 Volts for 3-4 hours. After electrophoresis, gels were washed to remove SDS and incubated for 60 minutes in renaturing buffer $(50 \mathrm{mM}$ Tris- $\mathrm{HCl} \mathrm{pH}$ 8.0, 2.5\% Triton X-100, $100 \mathrm{mM} \mathrm{NaCl}$ and $10 \mathrm{mM} \mathrm{CaCl}_{2}$ ) at $37{ }^{\circ} \mathrm{C}$ for $20-24$ hours. Then the gels were treated with fixing buffer (12\% acetic acid and 50\% methanol) for 30 minutes and subsequently stained with Coomassie brilliant blue R-250. Gels were destained in the mixture of distilled water, $7 \%$ acetic acid and $40 \%$ methanol until visualization of clear bands. The gel was documented by a gel documentation system (Bio-Rad Laboratories, United Kingdom) and analyzed by ImageJ software. The percentages of MMPs inhibition in comparison to the control (the untreated system) were calculated using the following equation:

$$
\begin{aligned}
\text { Inhibition }(\%)= & {[(\text { MMPs content of control }- \text { MMPs content of sample }) /} \\
& \text { MMPs content of control }] \times 100 \% \text {. }
\end{aligned}
$$

\section{Determination of total phenolic content}

The longan leaf extracts were determined for total phenolic content using Folin-Ciocalteu's reagent following the protocol of Bobo-Garcia et al., 2015. Gallic acid was used as a standard. Each sample $(10 \mu \mathrm{l})$ was dissolved in ethanol and mixed with $10 \%$ Folin-Ciocalteu reagent in deionized water $(100 \mu \mathrm{l})$. Then, 9.5\% sodium carbonate solution $(90 \mu \mathrm{l})$ was added and left at room temperature 
for 30 minutes. The absorbance of the mixture was determined at $765 \mathrm{~nm}$ using a microplate reader (SPECTROstar Nano ${ }^{\circledR}$, Ortenberg, Germany). The absorbance of the extracts was compared with gallic acid calibration curve and presented as Gallic acid equivalent (GAE) value in terms of $\mathrm{mg}$ gallic/g of the extract.

\section{Determination of total flavonoid content}

The longan leaf extracts were determined for total flavonoid content using the method of Herald et al., (2012) with some modifications. Quercetin was used as a standard. The extracts were dissolved in ethanol at the concentration of 1 $\mathrm{mg} / \mathrm{ml}$. The extract solution $(25 \mu \mathrm{l})$ was mixed with deionized water $(100 \mu \mathrm{l})$ and 5\% sodium nitrite $(10 \mu \mathrm{l})$. After 5-minute incubation, $10 \%$ aluminum chloride and $4 \%$ sodium hydroxide solution were added to the mixture. The absorbance of the solution was determined at $510 \mathrm{~nm}$ using a microplate reader (SPECTROstar $\mathrm{Nano}^{\circledR}$, Ortenberg, Germany) and compared with quercetin calibration curve. Quercetin equivalent $(\mathrm{QE})$ values of the extract were presented as mg quercetin/g of extract.

\section{High-performance liquid chromatography (HPLC) analysis}

The bioactive extract was selected for fingerprint study using Hitachi HPLC series L (Tokyo, Japan) equipped with Qchrome software. The HPLC system used consisted of a pump (Hitachi L-7100), a detector (Hitachi L-7420), an autosampler (Hitachi L-2200) and a column (Agilent $\left.{ }^{\circledR} \mathrm{C} 18,5 \mu \mathrm{m}\right)$ with an internal diameter of $4.6 \mathrm{~mm}$ and length of $250 \mathrm{~mm}$. Sample $(5 \mathrm{mg} / \mathrm{ml})$ was filtrated through a $0.45 \mu \mathrm{m}$ filter before injection into the HPLC column. The injection volume was $20 \mu \mathrm{l}$. A gradient elution A, composed of acetonitrile, and solution $\mathrm{B}$, consisting of $0.1 \%$ orthophosphoric acid, delivered at a flow rate of $0.8 \mathrm{ml} / \mathrm{min}$ as follows: $0 \mathrm{~min}: 10 \%$ (A); $60 \mathrm{~min}: 30 \%$ (A). The absorbance was chosen to record at 280 and $360 \mathrm{~nm}$ due to the UV spectra of the extract.

\section{Cell viability activity by the MTT assay}

The extracts at concentrations of $0.1-1 \mathrm{mg} / \mathrm{ml}$ in DMEM were tested for cell viability activity on mouse embryonic fibroblasts (BCRC 60071; ATCC $^{\circledR}$ CCL92) by the MTT assay according to the method of Chen et al., (2008). Ascorbic acid $(20 \mu \mathrm{g} / \mathrm{ml})$ was used as positive control. The cells were plated at a density of $1 \times 10^{5}$ cells/well in 96-well plates and left for cell attachment on the plate overnight in $5 \% \mathrm{CO}_{2}$ at $37{ }^{\circ} \mathrm{C}$. Cells were then exposed to the extract for 48 hours. After incubation, the cells were treated with MTT solution and then incubated at $37{ }^{\circ} \mathrm{C}$ for an additional 4 hours. The medium containing MTT was discarded, and MTT formazan that had been produced was extracted with DMSO $(1 \mathrm{ml})$. The absorbance was read at $570 \mathrm{~nm}$ using spectrophotometer microplate reader. The cell viability was calculated using the following equation:

$$
\% \text { cell viability }=\left[\mathrm{OD}_{570}(\text { Sample }) / \mathrm{OD}_{570}(\mathrm{Control})\right] \times 100
$$


where $\mathrm{OD}_{570}$ (sample) was the absorbance of the treated cells at $570 \mathrm{~nm}$ and $\mathrm{OD}_{570}$ (control) was the absorbance of the negative control at $570 \mathrm{~nm}$ (treatedDMSO cells).

\section{Statistical analysis}

Statistical analysis was performed by one-way ANOVA using SPSS statistics 17.0 program. All assays were done in the triplicate experiment. The results were demonstrated as the mean \pm standard deviation (S.D.) from three independent analyses. $P$-values of less than 0.05 were considered statistically significant.

\section{RESULTS}

The percentage yields and physical appearances of longan leaf extracts using two different solvents were shown in Table 1. HE showed a higher yield of $15.88 \pm 2.43$ (\%w/w of dry powder). HE exhibited different physical appearances from ET as shown in brown color and distinct odor.

\section{Determination of antioxidant activity}

DPPH assay has been accepted as an antioxidant screening test for a natural substance (Chang et al., 2011). While $\mathrm{H}_{2} \mathrm{O}_{2}$ is one type of ROS which human beings are exposed to from the environment, it is rapidly decomposed into oxygen and water. $\mathrm{H}_{2} \mathrm{O}_{2}$ may produce hydroxyl radical $(\mathrm{OH})$ that can initiate lipid peroxidation and cause DNA damage in the body (Alam et al., 2013). The $\mathrm{IC}_{50}$ values of DPPH radical scavenging assay, hydrogen peroxide scavenging assay and inhibition on lipid peroxidation were shown in Table 2. Both extracts showed remarkable activity on both DPPH radical scavenging and hydrogen peroxide scavenging. The inhibition on lipid peroxidation could not be detected on ET.

\section{Determination of anti-hyaluronidase activity}

D. longan leaves were reported to contain gallic acid, which exhibited hyaluronidase inhibitory activity (Florin et al., 2009). The $\mathrm{IC}_{50}$ values of the extracts were shown in Table 2. HE showed anti-hyaluronidase activities with $\mathrm{IC}_{50}$ of $234.80 \pm 21.52 \mu \mathrm{g} / \mathrm{ml}$, which was more potent than gallic acid, quercetin and ET that gave $\mathrm{IC}_{50}$ values of $521.30 \pm 67.12,568.87 \pm 21.44$ and $946.72 \pm$ $21.44 \mu \mathrm{g} / \mathrm{ml}$, respectively. Therefore, the active compounds of the extracts on anti-hyaluronidase activity might be more potent than gallic acid due to the activities themselves or synergistic effects.

Table 1. Yield of D. longan leaf extracts.

\begin{tabular}{lcl}
\hline \multicolumn{1}{c}{ Extracts } & Yield \% $(\mathbf{w} / \mathbf{w})$ & Physical appearances \\
\hline Ethanolic extract (ET) & $11.57 \pm 1.05$ & Sticky and dark green \\
Hydroethanolic extract (HE) & $15.88 \pm 2.43$ & Sticky and dark brown \\
\hline
\end{tabular}




\section{Determination of anti-collagenase activity}

The $\mathrm{IC}_{50}$ values of collagenase inhibition were shown in Table 2. ET and HE showed the inhibitory effect with the $\mathrm{IC}_{50}$ at $405.03 \pm 61.22$ and $314.44 \pm$ 62.14 , respectively. The extracts exhibited about 5 times lower activity than gallic acid. Regarding to the test extracts were mixing compounds, gallic acid might be one of the active ingredients for anti-collagenase activity.

Table 2. $\mathrm{IC}_{50}$ values of antioxidant, anti-hyaluronidase and anti-collagenase activities of $D$. longan leaf extracts and standards.

\begin{tabular}{|c|c|c|c|c|c|}
\hline \multirow[b]{3}{*}{ The extracts } & \multicolumn{5}{|c|}{$\mathrm{IC}_{50}(\mu \mathrm{g} / \mathrm{ml})$} \\
\hline & \multicolumn{3}{|c|}{ Antioxidant activity } & \multirow[b]{2}{*}{$\begin{array}{c}\text { Anti- } \\
\text { hyaluronidase } \\
\text { assay }\end{array}$} & \multirow[b]{2}{*}{$\begin{array}{c}\text { Anti- } \\
\text { collagenase } \\
\text { assay }\end{array}$} \\
\hline & $\begin{array}{c}\text { DPPH } \\
\text { radical } \\
\text { scavenging } \\
\text { assay } \\
\end{array}$ & $\begin{array}{c}\mathrm{H}_{2} \mathrm{O}_{2} \\
\text { scavenging } \\
\text { assay }\end{array}$ & $\begin{array}{l}\text { Inhibition of } \\
\text { linoleic acid } \\
\text { peroxidation } \\
\text { assay }\end{array}$ & & \\
\hline Ethanol extract (ET) & $27.92 \pm 3.39^{\mathrm{a}}$ & $48.90 \pm 16.37^{c}$ & ND & $964.72 \pm 74.91^{j}$ & $405.03 \pm 61.22^{\mathrm{n}}$ \\
\hline Hydroethanol extract (HE) & $30.03 \pm 7.64^{\mathrm{a}}$ & $71.40 \pm 15.30^{\mathrm{e}}$ & $537.01 \pm 42.32^{\mathrm{h}}$ & $234.80 \pm 21.52^{\mathrm{k}}$ & $314.44 \pm 62.14^{\mathrm{n}}$ \\
\hline \multicolumn{6}{|l|}{ Standards } \\
\hline Trolox & $5.50 \pm 1.02^{\mathrm{n}}$ & $0.74 \pm 0.14^{\mathrm{f}}$ & $0.14 \pm 0.12^{\mathrm{i}}$ & - & - \\
\hline Gallic acid & $1.22 \pm 0.33^{c}$ & $5.42 \pm 2.41^{\mathrm{g}}$ & $0.23 \pm 0.19^{i}$ & $521.30 \pm 67.12^{\mathrm{m}}$ & $60.70 \pm 11.01^{\mathrm{p}}$ \\
\hline Quercetin & $2.73 \pm 0.49^{d}$ & $5.41 \pm 1.32^{\mathrm{g}}$ & $0.12 \pm 0.11^{\mathrm{i}}$ & $568.87 \pm 21.44^{\mathrm{m}}$ & - \\
\hline
\end{tabular}

Note: In each column, different superscripts represent significant differences $(P \leq 0.05)$. ND; Not detected.

\section{Determination of MMP-2 and MMP-9 inhibition}

The comparison of the inhibition of MMP-2 and MMP-9 between both extracts and gallic acid by zymography at a concentration of $1.0 \mathrm{mg} / \mathrm{ml}$ was shown in Figure 1. HE demonstrated MMP-2 and MMP-9 inhibition more potently than gallic acid. This result has also supported the potential of hydroethanolic extract from $D$. longan leaves for the anti-aging application.

\section{Determination of total phenolic and total flavonoid content}

Phenolic compounds that are widely found in herbs have been reported for their strong antioxidant activities (Mukherjee et al., 2011). GAE (Gallic acid equivalent value; $\mathrm{mg}$ of gallic/g of the extract) was used to express the total phenolic content of $D$. longan leaf extracts, which was calculated by gallic acid calibration curve following the linear equation $y=0.0026 x+0.0296$; correlation coefficient of $\mathrm{R}^{2}=0.9978$. QE (Quercetin equivalent value; $\mathrm{mg}$ of quercetin/g of the extract) was used to express the total flavonoid content of the extracts. The total flavonoid content of QE was calculated by quercetin calibration curve following the linear equation $\mathrm{y}=0.0001 \mathrm{x}+0.1194$; correlation coefficient of $\mathrm{R}^{2}=0.9914$. Quercetin values in comparison to GAE values of each extract are shown in Figure 2. HE presented significantly higher GAE values than ET in the 
same way as its activities. The result demonstrated that the activities of extracts might be involved with other phenolic compounds which were not flavonoids.

A
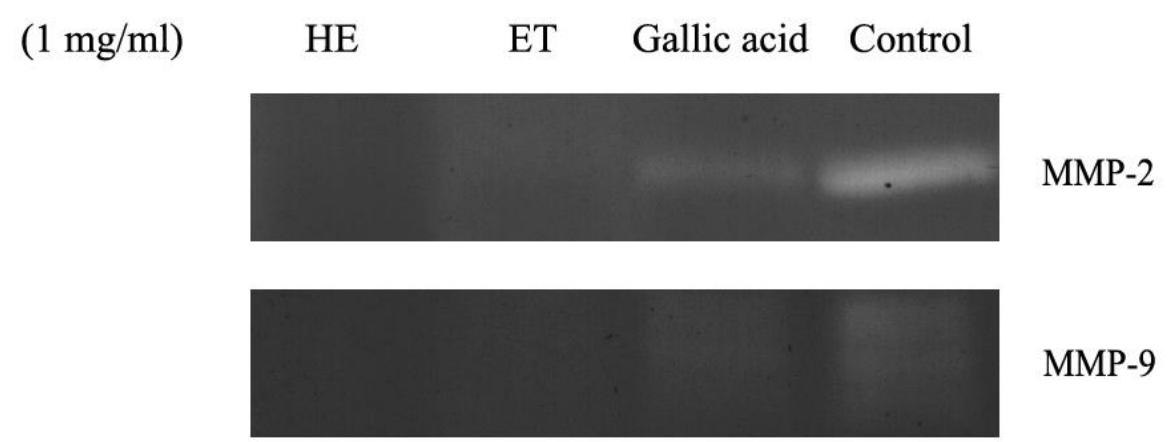

MMP-9

B
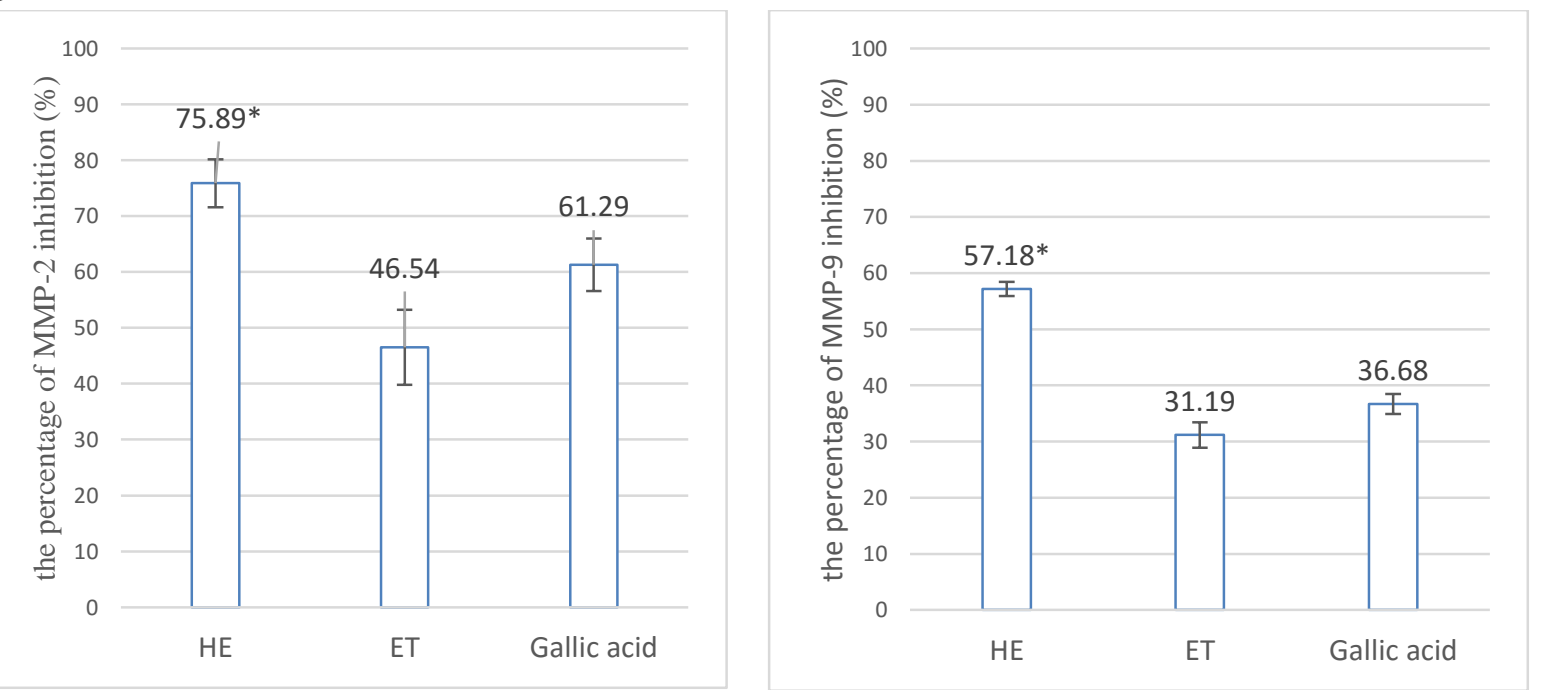

Figure 1. Comparison of the gelatinolytic activity on MMP-2 and MMP-9 between $D$. longan leaf extracts and gallic acid standard at $1 \mathrm{mg} / \mathrm{ml}$. (A) zymogram of the MMP-2 and MMP-9 in the experiments, (B) the percentages of MMP-2 and MMP-9 inhibition after 48-hour incubation at concentration of $1 \mathrm{mg} / \mathrm{ml}$; HE, Hydroethanolic extract; ET, Ethanolic extract.

Note:*HE showed significantly highest activity. The statistical significance of the differences between groups was determined using one-way ANOVA test. Statistical significance is assumed at $P<0.05$.

\section{High-performance liquid chromatography (HPLC) analysis}

HE was selected due to its remarkable biological activities for HPLC fingerprint study. The HPLC chromatogram was recorded at UV 280 and $360 \mathrm{~nm}$ as shown in Figure 4 which was compared with the retention time of gallic acid and ellagic acid. At $280 \mathrm{~nm}$, the retention time of gallic acid and ellagic acid were 5.626 and 30.512 minutes, respectively. The HPLC chromatogram of HE demonstrated one major peak at the retention time of 25.513 minutes which was neither gallic acid nor ellagic acid. At $360 \mathrm{~nm}$, the HPLC chromatogram 
demonstrated two significant peaks at the retention time of 30.607 minutes, which was ellagic acid, and the other of 39.26 minutes. As the consequence of the ellagic acid's area under the curve of both wavelengths, which showed nearly the same amount as shown in Figure 3, the peak of ellagic acid could be recognized as a marker for extract standardization.

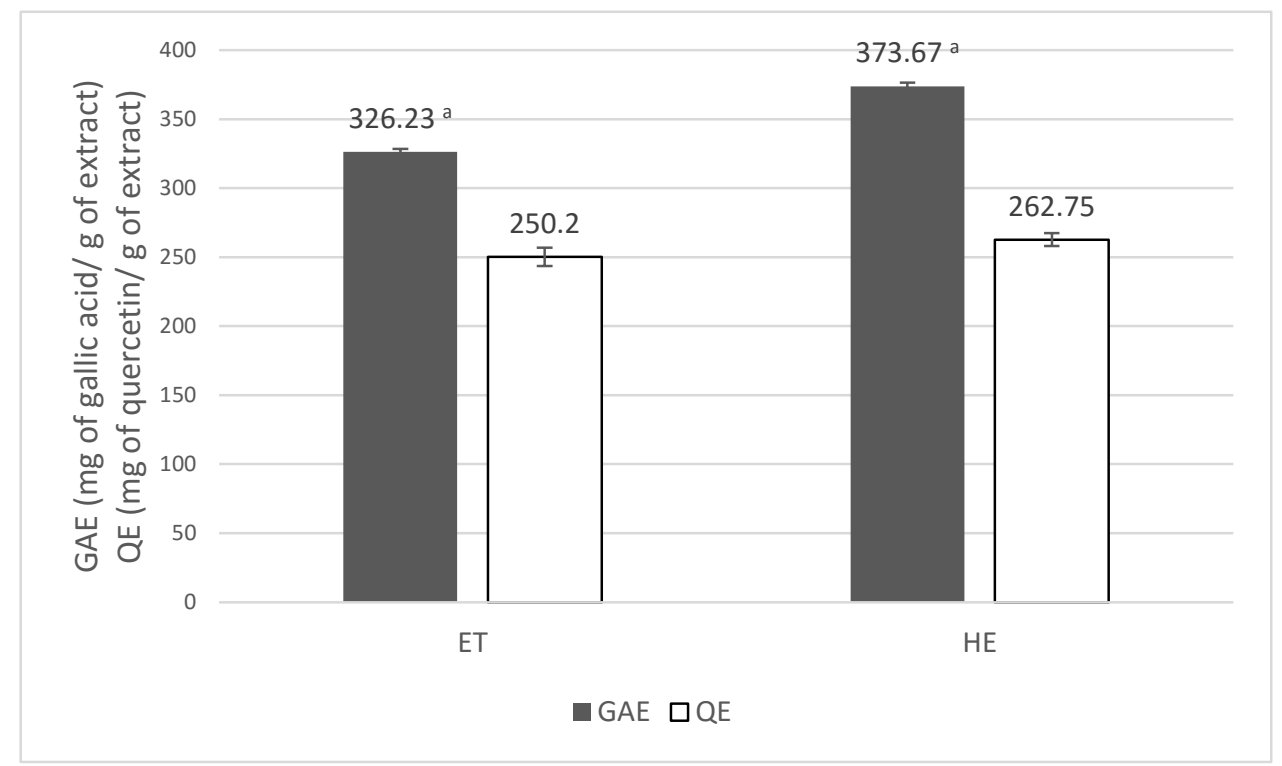

Figure 2. Comparison of GAE values ( $\square$ ) and QE values ( $\square$ ) of D. longan leaf extracts.

Note: ${ }^{\text {a }}$ HE showed significantly higher GAE than ET. The statistical significance of the differences between groups was determined using one-way ANOVA test. Statistical significance is assumed at $P<0.05$.

\section{Cell viability activity by the MTT assay}

From in vitro investigation of the anti-aging activity, HE was selected to be investigated for cell viability activity on mouse embryonic fibroblast cells. The cell viability of the samples was shown in Table 3 and the characteristic of the treated cells were shown in Figure 4. The extract of all three concentrations gave the acceptable cell viability.

Table 3. Cell viability of $\mathrm{HE}$ at concentration of 100,500 and $1,000 \mu \mathrm{g} / \mathrm{ml}$ and ascorbic acid in mouse embryonic fibroblast cells.

\begin{tabular}{lcc}
\hline \multicolumn{1}{c}{ Samples } & Concentration $(\boldsymbol{\mu g} / \mathbf{m l})$ & Cell viability $(\boldsymbol{\%})$ \\
\hline Hydroethanolic extract $(\mathrm{HE})$ & 100 & $78.0 \pm 3.7$ \\
& 500 & $79.7 \pm 2.8$ \\
Ascorbic acid & 1,000 & $79.3 \pm 2.4$ \\
Control & 20 & $89.0 \pm 0.4$ \\
\hline
\end{tabular}



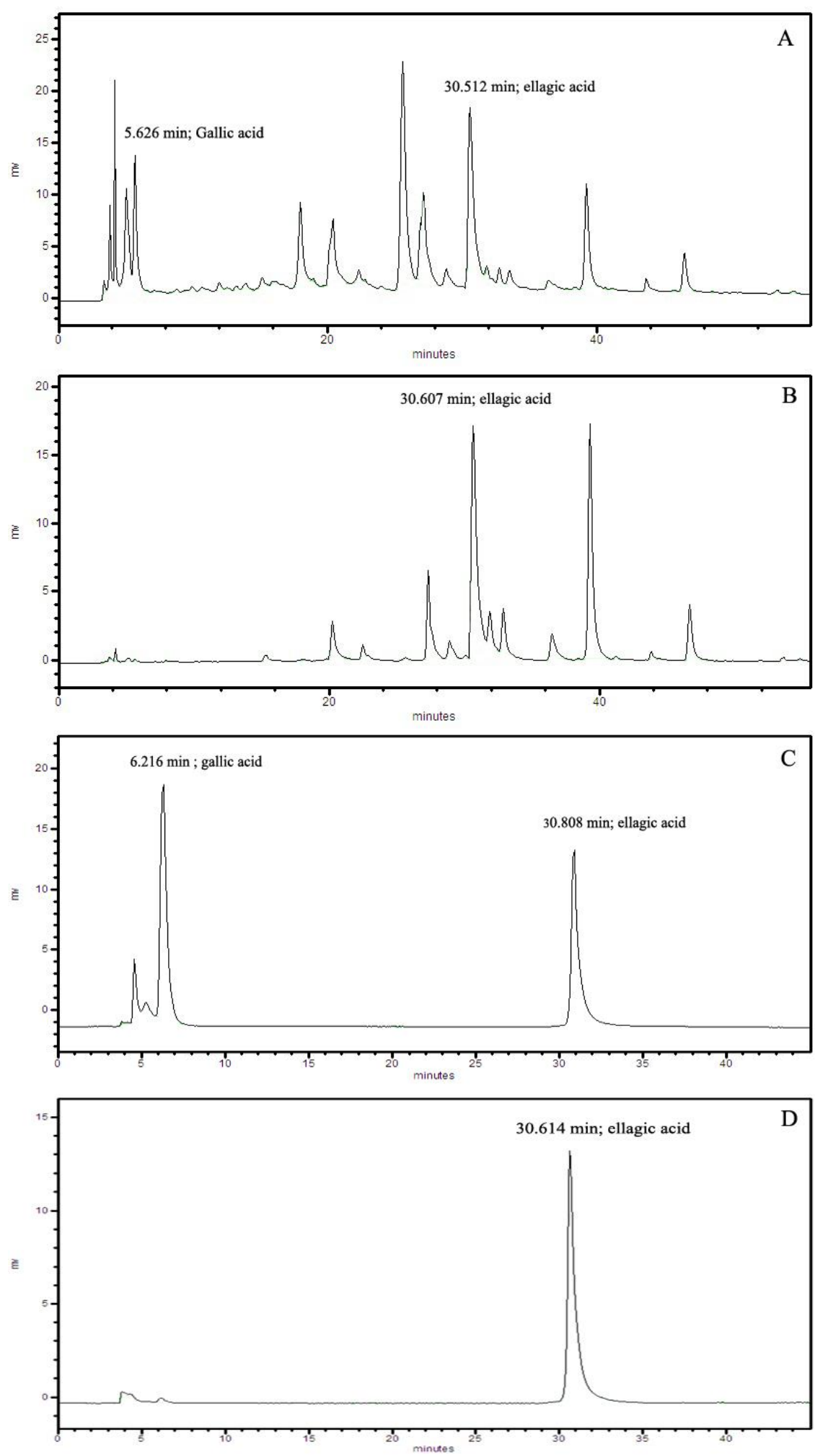

Figure 3. The HPLC chromatogram of the hydroethanolic D. longan leaf extract compared with the HPLC chromatogram of the mixture of $50 \mathrm{ppm}$ gallic acid and 50 ppm ellagic acid. (A) HPLC chromatogram of the extract at $280 \mathrm{~nm}$; (B) HPLC chromatogram of the extract at $360 \mathrm{~nm}$; (C) HPLC chromatogram of the standard mixture at $280 \mathrm{~nm}$; (D) HPLC chromatogram of the standard mixture at $360 \mathrm{~nm}$. 


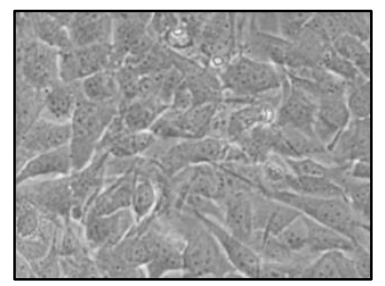

(A)

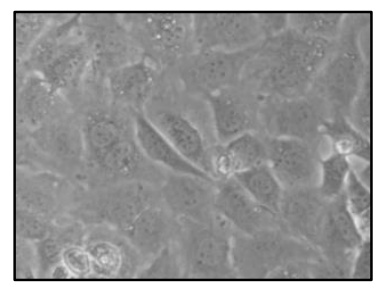

(B)

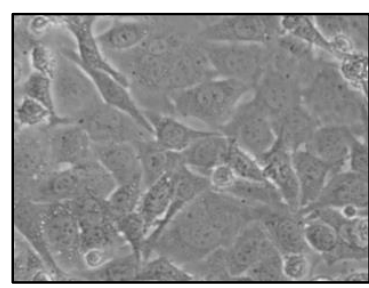

(C)

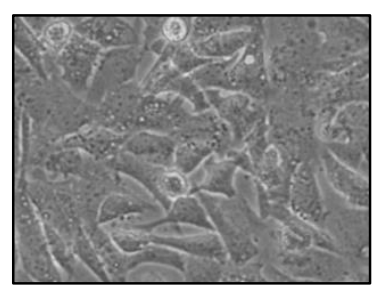

(D)

Figure 4. The characteristic of the mouse embryonic fibroblast cells treated with the hydroethanolic D. longan leaf extract. (A) Non-treated cells; (B) Treated cells with $100 \mu \mathrm{g} / \mathrm{ml}$ of extract; (C) Treated cells with 500 $\mu \mathrm{g} / \mathrm{ml}$ of extract; (D) Treated cells with $1,000 \mu \mathrm{g} / \mathrm{ml}$ of extract.

\section{DISCUSSION}

This present study demonstrates the potential of $D$. longan leaf extract for anti-aging properties via antioxidation and inhibition of hyaluronidase, collagenase, MMP-2 and MMP-9. Ethanol was selected as a potential extraction solvent for its wide range of natural compound extraction capability and safety for human consumption while $50 \%$ aqueous ethanol was selected as it was reported to have better polyphenol extraction (Madhan et al., 2007). For antioxidant activity, Chen et al. (2017) have shown that the $40 \%$ ethanol longan leaf extract could scavenge ABTS radical equivalent to $582.37 \mu \mathrm{mol}$ of Trolox standard. Moreover, it also showed Ferric reducing antioxidant power (FRAB) value equivalent to $182.58 \mu \mathrm{mol}$ of Trolox standard. Wu et al. (2013) revealed the antioxidant activities of purified polyphenol compounds from the leaves of longan. All the compounds exhibited strong radical-scavenging activities and chelating ability on ferrous. Our results revealed that both ET and HE extracts showed remarkable activity on DPPH radical scavenging and hydrogen peroxide scavenging assays. For the inhibition on lipid peroxidation, hyaluronidase, collagenase, MMP-2 and MMP-9 activities, HE showed significantly higher activity compared with ET. Besides, HE showed greater activity over gallic acid in anti-hyaluronidase as the same MMP-2 and MMP-9 inhibition. Although D. longan leaves were reported to contain gallic acid, but the other active compounds for anti-aging in the leaf might be more potent than gallic acid due to the activities themselves or synergistic effects of other phenolic or active compounds consisting in the extracts. While inhibition of collagenase activity of $D$. longan leaf extract has not been reported to date, Panyathep et al. (2013) revealed the inhibition of MMP-13 of D. longan seed extracts. The gallic acid-enriched and ellagic acid-enriched seed fraction seemed to have more inhibitory potency than gallic acid or ellagic acid. In contrast to this experiment, HE, containing gallic acid and ellagic acid, exhibited collagenase inhibition 5 times lower than a gallic acid standard. As the result of mixed type 
collagenase (MMP-1, -8, -13), gallic acid might be the active compound on MMP-1 or MMP-8 which is needed to be further investigated.

According to Xue et al. (2015) and Wu et al. (2013), when isolated and identified, the chemical constituents of longan leaves contained the presence of polyphenols such as quercetin, kaempferol, afzelin, (-)-epicatechin and proanthocyanidin A-2. Moreover, they have also been reported of triterpenoids and sterols. Comparing the inhibition on lipid peroxidation, hyaluronidase, collagenase, MMP-2 and MMP-9 activities of HE with ET, the active compounds may be more polar and hydrophilic. Determination of total phenolic and total flavonoid content showed a chemical profile of HE with significantly higher GAE value than ET but not for QE value which implied that HE consisted of more polar active compounds than ET. Consequently, the activities of the extract might be involved in other phenolic compounds which were not flavonoids. Ellagic acid was chosen to be recognized as a marker only for extract standardization. For the identification of the active compounds, HE needs to be further isolated and tested.

\section{CONCLUSION}

This present study has demonstrated the in vitro anti-aging capabilities of D. longan leaf extracts. The hydroethanolic extract possessed a potential for the in vitro antioxidation and inhibition of enzymatic activities. The extract revealed the activities that were correlated to its phenolic and flavonoid contents. Moreover, it showed the acceptable cell viability on mouse embryonic fibroblast cells. It might be a promising approach for further development into anti-aging products. As a consequence of its anti-hyaluronidase activity, which was better than gallic acid, HE was worthy of further isolation and testing of the active compounds.

\section{ACKNOWLEDGEMENT}

The authors sincerely thank the TA/RA Graduate Education Scholarship, Chiang Mai University, Chiang Mai 50200, Thailand for financial support, the Faculty of Pharmacy, Chiang Mai University and the Department of Cosmetic Science and Institute of Cosmetic Science, Chia Nan University of Pharmacy and Science for all facilities.

\section{REFERENCES}

Alam M.N., Bristi, N.J., and Rafiquzzaman, M. 2013. Review on in vivo and in vitro methods evaluation of antioxidant activity. Saudi Pharmaceutical Journal. 21: 143-152. https://doi.org/10.1016/j.jsps.2012.05.002 
Apriyanto, D.R., Aoki, C., Hartati, S., Hanafi, M., Kardono, L., and Arsianti, A., Louisa, M., Sudiro, T.M., Dewi, B.E., Sudarmono, P., et al. 2016. Antihepatitis $\mathrm{C}$ virus activity of a crude extract from Longan (Dimocarpus longan Lour.) leaves. Japanese Journal of Infectious Disease. 69(3): 213220. http://doi.org/10.7883/yoken.JJID.2015.107

Barla, F., Higashijima, H., Funai, S., Sugimoto, K., Harada, N., Yamaji, R., Fujita, T., Nakano, Y., and Inui, H. 2009. Inhibitive effects of alkyl gallates on hyaluronidase and collagenase. Bioscience, Biotechnology, and Biochemistry. 73(10): 2335-2337. https://doi.org/10.1271/bbb.90365

Bobo-Garcia, G., Davidov-Pardo, G., Arroqui, C., Vireda, P., Marin-Arroyo, M.R., and Navarro, M. 2015. Intra-laboratory validation of microplate methods for total phenolic content and antioxidant activity on polyphenolic extracts, and comparison with conventional spectrophotometric methods. Journal of the Science of Food and Agriculture. 95(1): 204-209. https://doi.org/10.1002/jsfa.6706

Chang, L., Juang, L., Wang, B., Wang, M., Tai, H., Hung, W., Chen, Y., and Huang, M. 2011. Antioxidant and antityrosinase activity of mulberry (Morus alba L.) twigs and root bark. Food and Chemical Toxicology. 49(4): 785-790. https://doi.org/10.1016/ j.fct.2010.11.045

Chen, G.L., Zhang, X., Cheng, S.G., Han, M.D., and Gao, Y.Q. 2017. Antioxidant activities and contents of free, esterified and insoluble-bound phenolics in 14 subtropical fruit leaves collected from the south of China. Journal of Functional Foods. 30: 290-302. https://doi.org/10.1016/j.jff.2017.01.011

Chen, T.Y., Wang, G.H., Cheu, T.H., Cheng, D.L., Chen S.C., and Liang C.H. 2008. Cytotoxicity effects of cembranoids from Formosan soft corals Sinularia notanda and Sinularia variablilis [dissertation]. [Tainan (Taiwan)]: University of Chia Nan.

Davies, A. 2008. Management of dry skin conditions in older people. British Journal of Community Nursing. 13(6):250-257. https://doi.org/10.12968/ bjen.2008.13.6.29456

Denicola, A., and Lopez-Alarcon, C. 2013. Evaluating the antioxidant capacity of natural products: a review on chemical and cellular-based assays. Analytica Chimica Acta. 763: 1-10. https://doi.org/10.1016/j.aca.2012.11. 051

Herald, T., Gadgil, P., and Tilley, M. 2012. High-throughout microplate assays for screening flavonoid content and DPPH-scavenging activity in sorghum bran and flour. Journal of the Science of Food and Agriculture. 92(11): 2326-2331. https://doi.org/10.1002/jsfa.5633

Jenkins, G. 2002. Molecular mechanisms of skin ageing. Mechanisms of Ageing and Development. 123(7): 801-810. https://doi.org/10.1016/S00476374(01) 00425-0 
Kiattsin, K., Nantarat, T., and Leelapornpisid, P. 2016. Evaluation of antioxidant and anti-tyrosinase activities as well as stability of green and roasted coffee bean extracts from Coffea arabica and Coffea canephora grown in Thailand. Journal of Pharmacognosy and Phytotherapy. 8(10):182-192. https://doi. org/10.5897/JPP20160413

Kim, Y., Chung, C., Kim, J., Ko, K., Park, S., Kim, J., Eom, S., Kim, Y., Hwang, Y., and Kim, K. 2008. Anti-wrinkle activity of Ziyuglycoside I isolated from a Sanguisorba officinalis root extract and its application as a cosmeceutical ingredient. Bioscience, Biotechnology, and Biochemistry. 72(2): 303-311. https://doi.org/10.1271/ bbb.70268

Lai, M.T., and Lue, S.C. 2017. Multiple herbal extracts used in the skincare cream with anti-wrinkle effects [dissertation]. [Tainan (Taiwan)]: University of Chia Nan.

Madhan, B., Krishnamoorthy, G., Rao, JR., and Nair, B.U. 2007. Role of green tea polyphenols in the inhibition of collagenolytic activity by collagenase. International Journal of Biological Macromolecules. 41(1): 16-22. https:// doi.org/10.1016/j.ijbiomac.2006.11.013

Manuskiatti, W., and Maibach, H. 1996. Hyaluronic acid and skin wound healing and aging. International Journal of Dermatology. 35(8): 539-544. https:// doi.org/10.1111/j.1365-4362.1996.tb03650.x

Mukherjee, P., Maity, N., Nema, N., and Sarkar, B. 2011. Bioactive compounds from natural resources against skin aging. Phytomedicine. 19(1): 64-73. https://doi.org/10.1016/j.phymed.2011.10.003

Olszewska, M.A. 2011. In vitro antioxidant activity and total phenolic content of the inflorescences, leaves and fruits of Surbus Torminalis (L.) crantz. Acta Poloniae Pharmacetica - Drug Research. 68(6): 945-953.

Panyathep, A., Chewonarin, T., Taneyhill, K., and Vinitketkumnuen, U. 2013. Antioxidant and anti-matrix metalloproteinases activities of dried longan (Euphoria longana) seed extract. ScienceAsia. 39: 12-18. https://doi.org/ 10.2306/scienceasia1513-1874.2013.39.012

Rashed, K.N., and Fouche, G. 2013. Anticancer activity of Dimocarpus longan Lour. Leaf extracts In vitro and phytochemical profile. Greener Journal of Medicinal Plant Research. 1(1): 001-005.

Ruch, R.J., Cheng, S.J., and Klaunig, J.E. 1989. Prevention of cytotoxicity and inhibition of intercellular communication by antioxidant catechins isolated from Chinese green tea. Carcinogen. 10: 1003-1008. https://doi.org/ 10.1093/carcin/10.6.1003

Sheu, S., Fu, Y., Huang, W., Chen, Y., Lei, Y., Yao, C., Hsu, F., and Kuo, Tzong. 2016. Evaluation of xanthine oxidase inhibitory potential and In vivo hypouricemic activity of Dimocarpus longan Lour. Extracts. Pharmacognosy Magazine. 12(2): S206-S212. https://doi.org/10.4103/ 0973-1296.182176 
Takahashi, T., Ikegami-Kawai, M., Okuda, R., and Suzuki, K. 2003. A fluorimetric Morgan-Elson assay method for hyaluronidase activity. Analytical Biochemistry. 322: 257-263. https://doi.org/10.1016/j.ab.2003. 08.005

Wu Q., Wang, L., Yu, X., Sun, Y., and Jinag Y. 2013. Polyphenols from longan leaf and their radical-scavenging activity. $4^{\text {th }}$ International Conference on Food Engineering and Biotechnology. 50: 180-185. https://doi.org/10. 7763/IPCBEE.2013.V50.36

Xue, Y., Wang, W., Liu, Y., Zhan, R., and Chen, Y. 2015. Two new flavonol glycosides from Dimocarpus longan leaves. Natural Product Research. 29(2): 163-168. https://doi.org/10.1080/14786419.2014.971318

Yasmin, H., Kabashima, T., Rahman, M.S., Shibata, T., and Kai, M. 2014. Amplified and selective assay of collagens by enzymatic and fluorescent reactions. Scientific Reports. 4(4950): 1-8. https://doi.org/10.1038/srep04 950

Yuge, L. 2012. Antioxidant activity of longan (Dimocarpus longan) barks and leaves. African Journal of Biotechnology. 11(27): 7038-7045. https://doi. org/10.5897/AJB11.3297 